\section{A Biotecnologia no Brasil}

Nos últimos tempos, a Biotecnologia tem cada vez mais sido alvo de ótimas discussões nos setores produtivo, acadêmico e governamental. É constante a cobertura da mídia face aos grandes benefícios que a Biotecnologia pode trazer à humanidade: as constantes descobertas e novos produtos lançados no mercado, como alimentos, cosméticos, medicamentos, processos terapêuticos, testes de diagnóstico e biocombustíveis. As novas tecnologias desenvolvidas e em desenvolvimento, através de processos biotecnológicos, são sem dúvida fascinantes, intrigantes e desafiadoras.

Mas o que é biotecnologia? Considerando a Convenção sobre Diversidade biológica de 1992, podese considerar a biotecnologia como um conjunto de tecnologias que utilizam sistemas biológicos, organismos vivos e/ou seus derivados para a produção ou modificação de produtos e processos específicos, bem como para gerar novos serviços de alto impacto em diversos segmentos industriais. O conceito de biotecnologia moderna tem sido mais utilizado, envolvendo o uso de engenharia genética para a manipulação de genes na produção de anticorpos, no desenho de drogas, na modificação genética de plantas e animais (transgênicos), entre outros.

\section{Em quais áreas do conhecimento e produção a} biotecnologia é inserida e utilizada? A biotecnologia tem grande multidisciplinaridade e transversalidade, podendo envolver e converger a aplicação de conhecimentos de diversas disciplinas e áreas, como a fisiologia humana e vegetal, bioquímica, genética, informática, física, matemática, agricultura, agropecuária, estatística entre

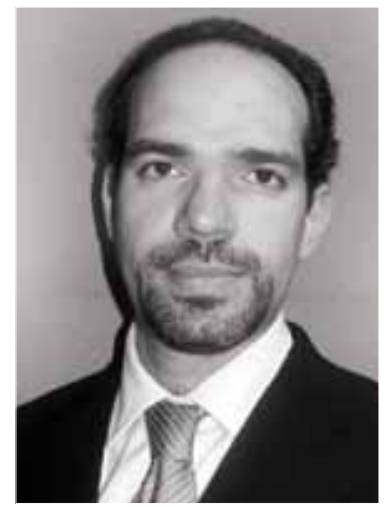

A grande parte de nossa competência técnica cientifica ligada à biotecnologia ainda está fixada na academia, ou seja, em universidades, centros de pesquisa e escolas técnicas.

outras. Cito abaixo alguns tópicos correlacionados a produtos, processos e pesquisas:

i. Bancos de Germoplasma: envolve a coleta e preservação de material genético de plantas e animais para preservação e utilização no futuro. Por exemplo, uma rara e específica planta que tem resistência a determinada praga pode ter esse gen identificado, isolado e inserido em outra planta.

ii. Biofármacos: produtos farmacêuticos e/ou medicamentos produzidos através de processos biotecnológicos. Diversos medicamentos são produzidos a partir de moléculas naturais embora hoje haja várias moléculas sintéticas originadas de plantas e/ou animais. Os exemplos mais clássicos são: a penincilina, a partir de fungos; um antinflamatório, a partir de plantas; um regulador de pressão sanguínea, a partir de toxina de veneno de serpente; um analgésico, a partir de veneno de um caramujo marinho; um controlador de diabetes e de peso, a partir da saliva de um lagarto, entre outros. Pode-se ainda incluir vacinas, enzimas e hormônios produzidos por rotas biotecnológicas.

iii. Biofísica: associação da física aos sistemas biológicos. Muito utilizada na medicina esportiva, nos aparelhos ortopédicos e para portadores de necessidades especiais, e na produção de calçados.

iv. Bioinformática: programas de computador, formação de bancos 
de dados, e modelagem molecular, que podem auxiliar em cálculos de reprodução de microorganismos para buscar, identificar e testar novas moléculas antes de ensaios com animais, entre outras;

v. Biomateriais: produtos com estruturas biológicas em sua composição. Podem ser utilizados: na construção completa ou parcial de órgão e tecidos; em linhas de sutura e colas biológicas utilizadas em cirurgias, absorvíveis pelo organismo; em malha de polímeros impregnada com células nervosas para reparação de lesões de medula, ou com células ósseas ou cartilagens para reparação de ossos e articulações; em ligas metálicas com revestimento biológico para implantes, articulações etc;

vi. Bioprospecção: busca de novas moléculas naturais originadas de plantas e/ou animais, com aplicações como terapêuticas (fitoterápicos e zooterápicos); utilização industrial (corantes e enzimas) e/ou na agricultura (plantas resistentes a doenças);

vii. Biotecnologia azul: refere-se a melhorias na produção de peixes e organismos aquáticos para a indústria de alimentos e farmacêutica;

viii. Células Tronco: estas células são como células matriz, que podem se diferenciar em outro tipo de célula de um organismo. Já estão sendo utilizadas experimentalmente e com relativo sucesso no tratamento de leucemias e doenças do coração;

ix. Clonagem: técnica de reprodução em que é produzido um organismo geneticamente idêntico ao que foi "copiado". Pode envolver diferentes ferramentas e técnicas biológicas para o melhoramento genético de animais e plantas que, copiados por clonagem, garantem a reprodução de organismos idênticos ao que foi produzido como, por exemplo, plantas melhoradas para resistir a pragas; animais com alta produtividade de carne ou leite; microorganismos modificados para produzir vacinas, etanol, proteínas e outros produtos biotecnológicos. É muito utilizada na produção de bananeiras e violetas;

x. Conversão de biomassa: biomassa é massa de material biológico de plantas ou animais, como: a cana-de-açúcar e soja após sua moagem; o esterco de gado; restos de microorganismos utilizados na produção de vacinas. A conversão desta biomassa pode ser feita para a obtenção de adubos, biodiesel, biogás, etc;

xi. Engenharia Tecidual: técnica de produção de tecidos que pode ser usada para a produção de: próteses completas ou apenas seu revestimento, minimizando o risco de rejeição; próteses; órgãos artificiais completos ou em parte como pele, osso, cartilagem entre outras aplicações, seja em laboratórios ou em outros animais. Também tem inúmeras aplicações em plantas;

xii. Genômica, Pós-genômica e Proteômica: envolvem o estudo dos genes (genoma), quais proteínas determinados genes produzem (pós-genômica) e as proteínas (proteômica) de plantas e/ou animais. A compreensão de suas estruturas e funções pode auxiliar na identificação e no tratamento de doenças até mesmo antes destas se manifestarem;

xiii. Nanobiotecnologia: pesquisa com organismos vivos em escala nanométrica, 1 milionésimo de metro (10-9) para produzir biomateriais, dispositivos e sistemas. Pode ser utilizada: na produção de chips (biochips) e CDs para aumentar a capacidade de armazenamento e processamento de dados; em testes laboratoriais e de imagem no diagnóstico de doenças; em cosméticos e medicamentos em que os produtos penetram até certa profundidade na pele e/ou têm sua liberação controlada conforme o tamanho das partículas utilizadas etc. É uma área que chama muita a atenção, inclusive dos autores de ficção científica, imaginando-se minirrobôs injetados no organismo para cirurgias não invasivas ou mesmo como armas;

xiv. Terapia Gênica: tratamento feito através da inserção de uma determinada função genética em células-alvo de um paciente, dando-lhes novas características que passarão a produzir proteínas para combater determinada enfermidade, em função de um problema congênito (de nascença) ou adquirido. O câncer e a esclerose múltipla têm sido um grande alvo destas pesquisas.

Mas o Brasil tem competências em todas estas áreas? Qual o nível de competência? Sim, o Brasil é competente em diversas destas áreas, mas com muitos desafios ainda por vencer. A grande parte de nossa competência técnico-científica ligada à biotecnologia ainda está fixada na academia, ou seja, em universidades, centros de pesquisa e escolas técnicas. As empresas ainda dão pouca prioridade para a contratação de mestres, doutores e pós-doutores para comporem seus quadros, sendo então poucas a utilizarem esta mão de obra altamente qualificada em seus centros de pesquisa e desenvolvimento. Em função desta concentração de competências e conhecimento fora das empresas, as pesquisas são desenvolvidas essencialmente nestes ambientes. A pouca integração entre os setores acadêmico e produtivo - umas das grandes barreiras que ainda temos - leva então a uma pequena ou mesmo nenhuma absorção e/ou transferência tecnológica dos resultados das pesquisas para setor produtivo, mantendo um nível aquém do desejado de competência técnica, científica e de inovação nas empresas nacionais. Muitas tecnologias desenvolvidas e com caráter altamente promissor e inovador não migram do balcão do laboratório acadêmico para estruturas de aumento de escala e, eventualmente, de desenvolvimento e produção para o mercado, atividades estas essencialmente desenvolvidas pelo setor produtivo. Se esta migração e absorção não aumentarem nos próximos anos, poderão repercutir em uma pequena possibilidade de as empresas nacionais terem produtos biotecnológicos no mercado nacional ou internacional. Assim, ficam cada vez menos competitivas, perdendo mercado e sendo absorvidas pelas que crescerem. 
Entretanto, o cenário é positivo no sentido de que esta integração tem aumentado, mesmo que paulatinamente. Considerando o setor agropecuário, este tem uma integração maior entre os setores acadêmico e produtivo e, assim, um maior percentual de resultados positivos no mercado. Outras empresas altamente inovadoras e que também mantêm estas parcerias têm tido excelentes resultados no uso de novas tecnologias desenvolvidas, soluções, inovações e lançamento de novos processos produtivos, aumentando significativamente sua competitividade no mercado.

Outras empresas altamente inovadoras e que também mantêm estas parcerias têm tido excelentes resultados no uso de inovações e soluções biotecnologias desenvolvidas, levando ao uso e/ou comercialização de novos processos e produtos, aumentando significativamente sua competitividade no mercado.

Quantas empresas e profissionais de Biotecnologia o Brasil tem? Qual o seu perfil? A Fundação Biominas, de Minas Gerais, publicou dois estudos em 2007 e 2009 (dados obtidos em 2006 e 2008, respectivamente) com um levantamento das empresas que atuam no setor de biotecnologia e/ou biociências no Brasil. Em 2007 listouse 71 empresas que atuam no setor em específico, e 181 na grande área de biociências. A região com a maior concentração de empresas de biotecnologia foi a sudeste, com 80,28\%; o Centro-oeste e Nordeste apresentaram $5,65 \%$ e a região sul $8,45 \%$. A região norte não apresentou registro.

Na publicação de 2009, foram caracterizadas 253 empresas de biociências, um aumento de 39,78\%. Cerca de 108 empresas (43\%) foram caracterizadas como atuantes em biotecnologia, apresentando um crescimento de 52,12\% de 2006 para 2008. A maioria das empresas tem menos de 10 anos de existência, e um número importante já faturou acima de $\mathrm{R} \$ 1$ milhão por ano. Entre as empresas de biociências, 73\% afirmaram interagir formalmente com universidades e institutos de pesquisa, e $66 \%$ destas depositaram ao menos uma patente, enquanto que dentre as que não interagem, apenas $25 \%$ fizeram ao menos um depósito. Ainda, $68,4 \%$ das empresas declararam que se beneficiam de instrumentos públicos de fomento para a inovação, como subvenção, isenção fiscal e crédito facilitado. Estas empresas são por certo ótimos casos de sucesso na utilização de parcerias e instrumentos de financiamento.

Em janeiro de 2010, os pesquisadores Emanuel Santos e Paulo de Andrade da UFPE - Universidade Federal de Pernambuco, identificaram 12 empresas atuantes no setor de biotecnologia no estado de Pernambuco. A maioria delas está instalada em incubadoras (comunicação pessoal). Isto significa um aumento de $100 \%$ considerando-se os números apresentados pelo estudo da Fundação Biominas em 2009.

Quando se faz uma busca de empresas cadastradas no Portal Inovação do MCT (Ministério da Ciência e Tecnologia), utilizando-se a palavra "biotecnologia" como chave, 82 empresas são identificadas como atuantes na área (acesso em fevereiro de 2010). A maioria destas empresas se cadastrou no portal para oferecer serviços e/ou para apresentar projetos à FINEP (Financiadora de Estudos e Projetos), buscando recursos para seus projetos, o que nos permite afirmar que elas têm característica de empresa inovadora. O número de profissionais que atua especificamente em biotecnologia é de difícil mensuração, dada a sua transversalidade, o que poderia levar à duplicidade se se utilizasse termos como os supracitados. Entretanto, ao fazer-se uma busca no Portal Inovação, em fevereiro de 2010, do número de currículos cadastrados na plataforma lates do $\mathrm{CNPq}$ (Conselho Nacional de Desenvolvimento Científico e Tecnológico) que apresentam o termo "biotecnologia" ao menos uma vez no filtro "competências", são identificados 10.098 nomes, sendo 5.738 (56,82\%) com pós-gradução em nível de doutorado e 2.214 (21,93\%) de mestrado. Usando o filtro por estado, identificou-se 188 profissionais baseados em Goiás. O portal inovação também pode fazer filtragens por associação de termos, como por exemplo biotecnologia + microorganismos, com 895 profissionais identificados, e biotecnologia + combustível, com 379 nomes, 3 (três) destes em Goiás. Qualquer instituição de ensino, pesquisa, empresa ou profissional, pode se cadastrar no portal ofertando ou mesmo solicitando serviços (bio) tecnológicos. Acadêmicos devem também inserir no Currículo Lattes os 
termos pertinentes à suas áreas de atuação e capacitação, para que sejam identificados nas buscas.

\section{Pesquisador, empresário ou ambos? É considerável} o número de empresas de Biotecnologia brasileiras que ainda são empresas tipo spin off, micro ou pequenas empresas, nascidas em incubadoras ou ligadas a universidades, o que pode estar em torno de $35 \%$, segundo dados do MDIC (Ministério do Desenvolvimento, Indústria e Comércio Exterior). Elas podem então ter sido criadas a partir de grupos de pesquisa ou mesmo pesquisadores independentes que conseguem dar início a pequenos processos de produção de produtos resultantes de suas pesquisas, e começam a conquistar mercados muitas vezes inexplorados. Embora estas situações sejam muito positivas por um lado, por outro eu tenho minhas reservas pessoais quanto a esse movimento. Este desvirtua o papel do pesquisador, que vê a necessidade de se tornar um gestor, se preocupando com impostos, contratação de pessoal, gestão de recursos humanos atuante no setor produtivo, gestão financeira, gestão de produção e outros processos de gestão. Esta migração provoca então a perda de pesquisadores em nível de estado da arte técnico-científica, que passa a gestor com alto risco de insucesso. O ideal seria o pesquisador pesquisando, o gestor administrando e ambos se beneficiando em parceria tipo ganha-ganha.

Qual a diferença técnica entre um pós-graduado e emgraduado? Comodevido respeito a ambososperfis, em se tratando de desenvolver algum projeto, o pós-graduado por certo tem vantagem, pois já possui: experiência de pesquisa e aprendizado na concepção e elaboração de um projeto; determinação e desenvolvimento de metodologia a ser seguida; experiência em identificar como e onde coletar dados bem como em sua organização e análise crítica; identificação e busca de solução de desvios de processos; discussão e defesa do trabalho realizado, entre outros. É claro que na graduação existe a experiência com a defesa de monografias, mas a escala é substancialmente maior em um programa de mestrado e, principalmente, de doutorado. Quando o profissional passa pelos crivos de defesa de dissertação em um mestrado, ou de uma tese em um doutorado, ele já "aprendeu a aprender" e o seu desenvolvimento em qualquer atividade, incluindo em uma equipe técnica do setor produtivo, será consideravelmente melhor. Não há dúvidas de que ambos os níveis necessitam de se adequarem para atuar no setor produtivo, mas esta necessidade pode por certo ser minimizada ou mesmo anulada quando a pós-graduação é feita em parceria com uma empresa, ou quando o programa é um mestrado profissional que em princípio gerará um novo produto ou processo.

Se pensarmos em custos, conforme afirmado por alguns empresários, por certo o profissional pós-graduado terá um custo salarial e de encargos maior, mas, por outro lado, levará menos tempo para dar retorno financeiro à empresa, visto que sua capacidade de aprendizado e desenvolvimento é essencialmente melhor. Em um curto ou médio prazo, o balanço tem então maior possibilidade de se tornar positivo para os projetos da empresa. As empresas que absorvem profissionais pós-graduados para atuar em P, D \& I (Pesquisa, Desenvolvimento e Inovação) podem também obter incentivos fiscais do governo através de programas de incentivo a inovação, o que também minimizaria seus custos. Ainda, a presença de pós-graduados em uma equipe incentiva outros colaboradores a seguirem este caminho, o que gera o crescimento de um ambiente inovador na empresa. A agregação de valor á força de trabalho é eminente, que então necessitará menor tempo para desenvolver novos produtos ou processos. Dessa forma, dará à empresa maior agilidade e aumentará o valor de seus produtos no mercado, refletindo então na manutenção ou mesmo no aumento de sua competitividade e crescimento. Não podemos esquecer que uma empresa é o que tem em sua força de trabalho, ou seja, seus colaboradores. Se eles são competentes, inovadores e felizes, a empresa terá esta característica e, portanto, terá maior chance de competitividade e sucesso.

\section{Como o governo brasileiro apóia financeiramente} projetos em biotecnologia? Não só os projetos em biotecnologia como projetos de P, D \& I em outras áreas. $\mathrm{O}$ mecanismo é universal, mas a biotecnologia tem recebido atenção especial por ser considerada uma área portadora de futuro. Este apoio ocorre com aporte de recursos reembolsáveis ou não, ou incentivos fiscais, 
na redução de impostos em função dos investimentos em pesquisas. Os três formatos já ocorrerem a um tempo considerável no Brasil, mas ainda são pouco utilizados pelas empresas. Todos os mecanismos e programas dependem da apresentação de projetos bem estruturados e justificados aos editais de órgãos de fomento, como o CNPq, CAPES (Coordenação de Aperfeiçoamento de Pessoal de Nível Superior), FINEP e BNDES (Banco Nacional de Desenvolvimento Econômico e Social), os mais conhecidos, entre outros. No caso do CNPq e da CAPES têm programas que atendem, por meio de bolsas, universidades, centros de pesquisa e mesmo empresas de forma direta, mas são específicos aos recursos humanos. Os valores nem sempre são atraentes para profissionais do setor produtivo, o que pode ser contornado pela empresa recipiente, pois são muito atraentes na desoneração de investimentos em projetos de P, D \& I.

AFINEPeoBNDES têmprogramasquedisponibilizam recursos não reembolsáveis e reembolsáveis de custo abaixo do mercado financeiro para custeio de projetos, desonerando até $95 \%$ do custo total, em montantes que podem chegar a R $\$ 10$ milhões, dependendo do caso. A participação de pós-graduados na gestão dos projetos tem sido um referencial constante para pontuar os projetos apresentados, e já sinalizou uma tendência de se tornar uma obrigatoriedade para determinados casos.

Uma outra forma de financiamento é a indireta, através das leis do bem e de inovação, que disponibilizam incentivos fiscais através de descontos no imposto de renda para empresas que mantêm programas de inovação internos, em parceria com universidades e/ou pela contratação de mestres e doutores. Esta ferramenta é extremamente subutilizada, apesar de ter havido um crescimento nos últimos anos desde a criação das leis. A correta e segura utilização depende de uma gestão consideravelmente simples dos investimentos feitos em P, D \& I, também incluindo a elaboração de projetos estruturados, mas muitos empresários desconhecem esta ferramenta e deixam de receber milhares de reais todos os anos, o que permitiria desonerar seus investimentos.

Mais de 200 milhões de reais em recursos não reembolsáveis para projetos de biotecnologia foram disponibilizados entre os anos de 2004 e 2009 através de editais. Outros investimentos governamentais e privados devem ultrapassar os 2 bilhões de reais até o final de
2010.

Qual a importância para o setor de biotecnologia brasileiro, da interação tipo "tripla hélice", que envolvem empresa + universidade e centros de pesquisa + governo, ou entre empresas e universidades?

O ganho é sem dúvida universal. Quando o governo participa, é principalmente no sentido de fomento direto ou indireto, como citado acima, através principalmente do CNPq, da CAPES, FINEP e do BNDES. A academia participa disponibilizando: infraestrutura de altíssimo custo e tecnologia de ponta; acesso a outros centros de pesquisa em formato indireto, necessários a diversos projetos biotecnológicos, e pesquisadores de excelência e rigor técnico-científico, que terão baixo custo para a empresa. A empresa participa com: experiência de gestão; experiência de mercado; encomenda tecnológica e recursos financeiros diretos.

Diversas empresas nacionais e universidades estão amadurecendo no sentido de integração mútua, embora ainda há muito que melhorar neste sentido. $\mathrm{O}$ número de parcerias por certo tem crescido nos últimos anos, embora ainda seja tímido, e pode estar ocorrendo, entre outros fatores, por um maior entendimento e amadurecimento de ambos em relação aos seus verdadeiros papéis e aos prazos e às distribuições dos eventuais lucros e dividendos. Em experiências pessoais no Japão, presenciei a importância de haver o pesquisador pesquisando, e o gestor administrando, cada um em seu papel, otimizando a competência de cada um em prol do sucesso na execução dos projetos. $\mathrm{O}$ risco de insucesso é por certo considerável em vários destes projetos, mas há um ganho intrínseco que muitos empresários e pesquisadores deixam de contabilizar: o conhecimento tácito. Dado o alto risco de muitos projetos biotecnológicos, o retorno financeiro direto pode não ocorrer. Entretanto, o ganho indireto já tem sido mensurado em função da capacidade de inovação que as empresas desenvolvem, elevando seu potencial competitivo no mercado, conforme já discutido.

\section{Quais os desafios que ainda enfrentamos para o desenvolvimento da biotecnologia no Brasil?}

Em resumo, podemos discutir 5 (cinco) pontos principais: recursos humanos, infraestrutura, investimentos, aspectos de mercado e marcos 
regulatórios. Estes pontos foram elencados em meados de 2004 pela Política Industrial, Tecnológica e de Comércio Exterior (PITCE), e discutidos em 2 (dois) estudos publicados no final de 2009 sobre o setor de biotecnologia brasileiro, encomendados pela Agência Brasileira de Desenvolvimento Industrial (ABDI) ao Centro de Gestão e Estudos Estratégicos (CGEE).

i. Recursos Humanos: nós temos excelência técnica, conforme já discutido, mas precisamos capacitar os estudantes de graduação, pós-graduação e profissionais em um formato mais interdisciplinar, multidisciplinar, e em aspectos da inovação, como a gestão, o empreendedorismo, os projetos e as patentes. Alguns projetos em parceria têm enfrentado dificuldades ao longo da execução pela falta destes conhecimentos em ambos os lados: setor produtivo e academia. A fixação e atração de talentos nas empresas também são um gargalo devido à baixa remuneração oferecida;

ii. Infra-estrutura: Ainda existem dificuldades para se utilizar as estruturas das academias devido: à interação e aos mecanismos ainda incipientes; à falta de conhecimento dos processos de transferência e comercialização de tecnologias. São poucos os projetos induzidos pelo mercado através de encomendas tecnológicas, e é grande a dependência da importação de insumos e equipamentos básicos. Para as estruturas de apoio tecnológico, ainda necessitamos de mais centros de referência para ensaios pré-clínicos, imagem, coleções biológicas, biotérios, entre outros. Os serviços tecnológicos e os serviços em metrologia ainda são insuficientes, bem como a normalização e avaliação de conformidade, entre outros serviços técnicos especializados;

iii. Investimentos: os financiamentos estão se consolidando, mas ainda são irregulares, descontínuos e de baixo volume, com pulverização de recursos; falta foco no desenvolvimento de produtos/processos em projetos das áreas de fronteira; a iniciativa privada ainda tem baixa participação no uso destes recursos, e a avaliação e o monitoramento da aplicação dos recursos têm pouca informação quanto aos objetivos versus resultados. Sobre os investimentos em P\&D\&I, enfrentamos o baixo investimento privado e de capital empreendedor para a inovação em biotecnologia; temos dificuldades e custos elevados na importação de bens, produtos e serviços; iv. Aspectos de mercado: o poder de compra governamental ainda é pouco utilizado; é mínimo o conhecimento dos mercados das áreas de fronteira da biotecnologia, e o desenvolvimento das estratégias de mercado ainda é modesto ou inexistente;

v. Marcos Regulatórios: um desafio mundial que enfrenta as dificuldades de proteção intelectual dos produtos biotecnológicos (patentes) e os limites da ética em pesquisa com animais e seres humanos (bioética), entre outros.

Todos estes desafios estão sendo enfrentados e minimizados pouco a pouco pelos governos, pelos setores produtivo, acadêmico e pela população em geral, como pode ser verificado nas mudanças ocorridas nos últimos 5 (cinco) anos tanto no Brasil como no mundo. A simples discussão destes tópicos é um grande reflexo do desenvolvimento e amadurecimento de todos os atores envolvidos direta ou indiretamente, pois à medida que se cresce, novos desafios são encontrados, enfrentados, modificados ou mesmo transpostos. Em qualquer hipótese de transposição ou não das dificuldades, o resultado é sempre o crescimento, pois não existem fracassos, apenas aprendizados!

\section{Wilker Ribeiro Filho*}

Biólogo pela Univ. Federal de Goiás, doutor (PhD) em Ciências Médicas / Fisiologia pela Faculdade de Medicina da Universidade de Miyazaki, Japão; consultor de empresas em gestão de projetos de Pesquisa, Desenvolvimento e Inovação Tecnológica e Sistemas de Gestão de Qualidade; professor do Mestrado Profissional em Gestão, Pesquisa e Desenvolvimento Tecnológico Farmacêutico da PUC-GO/ UEG/UNIEVANGÉLICA; Especialista em Projetos - Biotecnologia, da Agência Brasileira de Desenvolvimento Industrial - ABDI.

*email: wilkersnake@hotmail.com 